\title{
Arcaísmo, cibercultura e reencantamento do mundo: as dobras do cotidiano tecnológico ${ }^{1}$
}

\author{
Archaism, cyberculture and re-enchantment of the world: the folding of daily \\ life technological
}

\author{
Arcaísmo, cibercultura y reencantamiento del mundo: los pliegues del \\ cotidiano tecnológico
}

\author{
Michel Maffesoli ${ }^{2}$
}

\begin{abstract}
Resumo
O projeto moderno do "tudo-tecnológico" mudou. Paradoxalmente, a tecnologia invade nossas vidas, mas, agora, introduzindo, devido a sua própria forma, características plurais inerentes tanto à magia quanto ao arcaísmo do ser humano. Este artigo, pois, seguindo o que poderíamos denominar "dobras do cotidiano tecnológico", navega, portanto, por questões que nos remetem aos paradigmas em Thomas Kuhn, à figura mítica do Golem na Cabala Judaica ou à cibercultura de variadas sincronias. Sincronicidade essa que, para Nietzsche, se dá no justo encontro entre nossas origens e o futuro.
\end{abstract}

Palavras-chave: Cibercultura. Cotidiano. Comunicação de Massa. Postmodernity.

\begin{abstract}
The modern "all-technological" design has changed. Paradoxically, technology invades our lives, but now introducing, by its very form, plural features inherent in both magic and the archetype of "human being". This article, therefore, following what we could call "folding of daily life technological", therefore, navigates for questions that refer us to the paradigms in Thomas Kuhn, to the mythical figure of the Golem in the Jewish Kabbalah or to the cyberculture of varied synchronies. Synchronicity that, for Nietzsche, occurs in the right encounter between our origins and the future.
\end{abstract}

Keywords: Cyberculture. Daily Life. Mass media. Postmodernity.

\section{Resumen}

El diseño moderno del "todo-tecnológico" ha cambiado. Paradójicamente, la tecnología invade nuestras vidas, pero ahora, introduciendo, debido a su propia forma, características plurales inherentes tanto a la magia y al arcaismo del "ser-humano". Este artículo, pues, siguiendo lo que podríamos denominar "pliegues del cotidiano tecnológico", navega, por lo tanto, por cuestiones que nos remiten a los paradigmas en Thomas Kuhn, a la figura mítica del Golem en la Cábala judaica o a la cibercultura de variadas sincronías. Sincronicidad aquella que, para Nietzsche, se da en el encuentro exacto entre nuestros orígenes y el futuro.

Palabras clave: Cibercultura. Cotidiano. Comunicación de massa. Posmodernidad.

\footnotetext{
${ }^{1}$ Tradução do francês por Eduardo Portanova Barros. Professor visitante do PPG em Comunicação da Faculdade de Informação e Comunicação da Universidade Federal de Goiás (UFG).

${ }^{2}$ Professor Emérito da Sorbonne e membro do Instituto Universitário da França. e-mail:

michelmaffesoli@gmail.com.
} 
ssa curiosa, misteriosa, mas não menos real sincronicidade entre as origens e o futuro, da qual Nietzsche nos fala, é, certamente, uma das características mais notáveis da pós-modernidade. Isso é exatamente o que eu designei, ao longo destas páginas, por um oxímoro: enraizamento dinâmico. Mas, como as rotinas filosóficas obscurecem os espíritos, é difícil admitir que o mito do Progresso, e o progressismo servindo como suporte teórico, possam dar lugar a outra relação com a natureza: a progressividade. O que não é regressão, mas "ingression”. Nós entramos neste mundo-aqui. Como já propôs Baudelaire, participamos das muitas correspondências específicas do "Grande templo da natureza". Afinal, não é uma sabedoria imemorial admitir que, à medida que alguma coisa se apaga, alguma outra coisa aparece? Isso é o que é progressividade. Não se contenta apenas em explicar o que somos e o mundo em que vivemos. Explicar (ex-plicare) é remover as dobras que constituem a consciência individual e o inconsciente coletivo. Não, a progressividade implica os estratos que constituem cada um e todas as sedimentações que fazem a cultura popular. E as várias palavras-chave que tenho, nas últimas décadas, propostas para reflexão: proxêmica, cotidiano, enraizamento, tribalismo, nomadismo e, ultimamente, "invaginação", pretendem dar atenção à realidade vivida, dia a dia, de tal implicação.

Há em todos esses termos, além de nossas ficções teóricas, algo que se refere ao afloramento do arcaísmo. Devemos lembrá-lo? Ao contrário do uso usual desse termo, o arcaico é o que é antigo, primeiro, fundamental. Não está de modo algum desatualizado, mas é a base do estar-junto. Em geologia, o afloramento ocorre quando um local ou uma rocha que serve de subsolo se forma. É o mesmo na "geossociologia". Além de nossas evidências intelectuais, deve-se notar que afloram os modos de pensar, as maneiras de ser, as práticas corporais que se acreditavam ultrapassadas pelo progressismo. Mas acontece que "a árvore em cuja sombra" Nietzsche "se aloja" não é mais a simples árvore do conhecimento cartesiano. Combina origem e futuro. O sítio geológico periférico lembra que toda construção precisa de fundações e que a construção social não lhe escapa. É somente porque existe um "dado" que é inútil negligenciar. Vã porque este dado, cada vez mais, lembra a nossa boa memória. Não queremos negá-lo porque, paradoxalmente, ele empresta esses canais que pensávamos serem apenas os do Progresso: a tecnologia. Eu voltarei a isso, mas quando se trata de "site" hoje em dia, é a internet que estamos nos referindo!

Em vários campos, e tendo objetivos muito diferentes, um sociólogo como Max Weber ou um historiador da ciência como Thomas Kuhn pode-se mostrar a estreita relação 
existente entre o racionalismo e o desenvolvimento científico e tecnológico. Acrescento o racionalismo como uma exacerbação ou sistematização da racionalidade, removendo todos os outros parâmetros humanos da esfera pública. Em um livro clássico que estabelece uma relação estreita entre o protestantismo e o capitalismo, refletindo sobre o surgimento da modernidade, Weber fala de "racionalização generalizada da existência". É isso que leva ao famoso "desencantamento do mundo". Que é apenas a causa e o efeito de uma existência em que toda a irregularidade foi banida, onde o natural definitivamente deu lugar ao artifício, na curta vida social completamente acéptica pela "violência totalitária" de uma tecnocracia puramente racional.

Por sua parte, Kuhn lembra que é tomando a via recta da razão que o Ocidente, em oposição a outras tradições culturais, vai direto ao ponto: o do desenvolvimento científico resultando na implantação tecnológica que nós conhecemos. Para tanto, vale destacar, observa-se esta marcha forçada em direção ao Progresso que vai, para aliviar, abandonar toda uma série de bagagens inúteis: esses impedimenta que são o sonho, o lúdico, o festivo. É tal abandono que garantirá a perfomatividade da civilização ocidental e seu triunfo no final do século XIX, sobre todos os outros. Trata-se de duas análises paradigmáticas. Mas há muitas outras neste sentido que permitem compreender, ao longo do século $\mathrm{XX}$, o triunfo planetário da tecnologia ou mesmo a tecnicização do mundo. Como o Golem da Cabala Judaica, que escapa ao controle de seu criador, que saqueou tudo ao seu redor, os objetos técnicos subordinarão a seus poderes cada momento da existência, sem que nada ou ninguém lhes escape. O trabalho e o tempo livre, a produção e o consumo, a educação e o esporte, todas as instituições que, gradualmente, se constituirão na sociedade se esforçarão para pôr em ordem, disciplinar afetos, instintos e as pulsões sob a égide da razão técnica.

Verifica-se que a maioria dos observadores sociais, fiel à sua base teórica, aquela dos séculos XVIII e XIX, continuam a gorjear o refrão de "desencanto" e alimentar-nos de análises sobre a melancolia e a alienação inelutáveis, uma consequência do controle tecnológico, com indícios diabólicos. Esses pregadores chatos que, do alto de suas cadeiras universitárias ou através de suas plataformas de mídia, trabalham para assustar otários crédulos, não percebem que "piar" nada mais é, em seu sentido etimológico, que os twitters. Nestes fóruns de discussão não se fala muita coisa a sério, é verdade, mas é onde a troca se estabelece. Nestes "chats", na verdade, o importante é estabelecer um link. O conteúdo importa pouco. O que está em jogo é a "religação": estar conectado (religare, em latim), estar em confiança (conectar, em inglês). 
É tudo isso, e muitas outras coisas, que me fazem afirmar que a tecnologia pósmoderna é parte do reencantamento do mundo. Certamente, isso pode parecer paradoxal. E isso é mesmo, em parte. Mas, mais uma vez, além de nossos a prioris teóricos, podemos constatar que o que "está em jogo", justamente, é o retorno desse lúdico que a modernidade, em sua marcha real de Progresso, havia marginalizado, confinado no quarto das crianças ou, pelo menos, no espaço estritamente privado. O jogo, portanto, ocupa um lugar de escolha na videoesfera. Para alguns, até o vício vigia. De qualquer forma, é uma realidade sobre a qual não podemos fazer economia. E essa estrutura antropológica lúdica, isto é, a estrutura com raízes profundas e antigas, encontra a ajuda do desenvolvimento tecnológico. É o mesmo, além disso, do sonho que não é mais, simplesmente, admissível, individualmente, no divã do psicanalista, mas que tende a contaminar muitas práticas societais: revoltas, rebeliões, fantasias, várias fantasmagorias, e isso todas as áreas. É isso que está em jogo (“en-jeu”), é isso que está em jogo (enjeu) em uma pós-modernidade da qual não podemos mais dizer, simplesmente, que é nascente, tamanha evidência de suas características na vida cotidiana. É, de fato, paradoxal, mas através de videogames, de homepages, na multiplicidade de twitters, é a linguagem das aves que prevalece. Não a das "nuvens" filosóficas, das quais Aristófanes mostrou abstração, mas a das fantasias da vida cotidiana. É realmente um reencantamento do mundo em questão, onde a realidade, talvez melhor seja "surrealismo", vai além da "ficção" um tanto mortífera, chata e, em muitos aspectos, defasada, da teoria racionalista.

Existe, de fato, o surrealismo vivido no uso diário dos meios de comunicação interativa. O virtual tendo, ao mesmo tempo, uma eficácia real, permitindo uma forma de prazer real, e desenvolvendo um elo, estabelecendo um elo, isto é, em seu pleno sentido, fazendo sociedade. E isso, a partir de duas características essenciais de nossa espécie animal, a capacidade de imaginar e, a partir daí o retorno à comunhão com o outro. É exatamente um status nascendi, um estado nascente, que está em ação em várias ciberculturas, contaminando, de muitas maneiras, o cotidiano de nossas sociedades. É realmente em termos epidemiológicos que o problema deve ser colocado. Tanto é verdade que, silenciosamente, mas teimosamente, os vários meios de comunicação interativos ganharam terreno e se impuseram. Ao mesmo tempo, no que diz respeito aos serviços, aos procedimentos administrativos ou burocráticos, mas também em todos os momentos lúdicos, onde o sonho tende a substituir a própria realidade.

Pode-se considerar que um dos momentos-chave dos Tempos Modernos foi essa circunavegação, onde exploradores ousados descobriram esses novos mundos e, assim, 
ampliaram as percepções usuais, as maneiras e as diversas imaginações de seus contemporâneos. Juristas de espírito agudo, como Carl Schmitt, mostraram como essa perambulação conceitual estava na origem do jus publicum Europaeum. Uma nova ordem de coisas foi elaborada nesta ocasião; um Nomos da terra, isto é, uma lógica interna, uma nova racionalidade do laço social sendo constituída através e graças às descobertas induzidas pela circunavegação em questão. Não podemos afirmar que algo assim está acontecendo a partir da navegação eletrônica: a descoberta de um Novo Mundo? O desenvolvimento de uma cultura totalmente diferente daquela que marcou a modernidade? Isso não será sem influência nos estilos de vida e nos imaginários sociais. Isto é o que destacam as pesquisas no Centro de Estudos sobre o Atual e o Cotidiano (www.ceaq-sorbonne.org) destaca, assim como as várias publicações de Stéphane Hugon sobre o assunto (stephane.hugon@)eranos.com).

Lembremo-nos de Thomas Kuhn, que, refletindo sobre as descobertas científicas e suas consequências tecnológicas, pôde mostrar como elas eram causa e efeito do que ele chamou de paradigma. Que podemos entender como uma matriz que, em seu sentido estrito, permite a eclosão de uma nova vida. É exatamente um novo paradigma que está, atualmente, em formação e que chamamos cibercultura. $\mathrm{O}$ indivíduo, como sabemos, não é redutível à sua parte emergente e apenas existe em função de um substrato inconsciente. É o mesmo para a vida social que, ela também, tem suas criptas mais ou menos labirínticas. Outra maneira de dizer o inconsciente coletivo. Uma raiz constante da cultura ocidental é o medo do pânico da imagem. Esta iconoclastia, de memória antiga, tem sido frequentemente analisada. Mas devemos analisar bem seus elementos essenciais para entender o medo inspirado hoje pelo mundo virtual.

Resumindo, lembremo-nos da luta dos profetas do Antigo Testamento contra ícones e outros ídolos feitos de pedra ou madeira. Combate feroz para alcançar um Deus único, a quem é aconselhável adorar em "espírito e verdade". O acento é posto no cérebro, o cognitivo. E a Verdade que alcança. O ídolo, do qual é importante lembrar que era de essência feminina, causa e efeito de cultos para a "mãe terra", o ídolo, portanto, não apelou para a razão, mas para o ventre. Há algo de histérico nela. É o usterus que é solicitado. O que é o ventre se não o símbolo dos sentidos em sua diversidade. $\mathrm{O}$ ventre, em sua posição central, é o sinal da inteireza do ser. Para usar um oxímoro instrutivo, é um vetor de uma razão sensível, combinando os opostos, trazendo-os em interação, em coincidência.

Posteriormente, lembremo-nos, que tal iconoclasmo se tornou filosófico com Descartes e Malebranche incitando ambos a desconfiar dessa imaginação como "a louca da 
casa". Isto é, não permitindo o funcionamento adequado da faculdade racional. É essa estigmatização que encontraremos ao longo da modernidade e que alimentará as várias convicções contra a imagem em geral, na publicidade, nos videogames, nas dramatizações e de que é inútil negar, hoje em dia, sua importância. Correlativamente ao iconoclasmo, também é importante enfatizar, por mais surpreendente que pareça, que uma das raízes do medo do virtual seja a condenação do onanismo. No quadro geral que, como sabemos, vai ser um dos valores dominantes da tradição judaico-cristã, a figura de Onan é, de certo modo, um paroxismo. Precisamente em que seu gozo é, aparentemente, individual, inútil. Sua semente está perdida na terra. Se olharmos mais de perto, a correlação é óbvia. Nessa masturbação é preciso contar uma história, fazer um cenário, enfim, visualizar imagens. A perda da semente na terra também é instrutiva, pois é feita em uma espécie de união cósmica. Um casamento místico com a terra, centro da união. Símbolo da comunidade humana!

Essas observações alusivas pretendem deixar claro que a cibercultura é tanto uma expressão do poder da imagem quanto do gozo inútil. O jogo do imaginário ocupa um lugar de escolha, e a dimensão onanista, no sentido que acabo de indicar, está longe de ser insignificante. A rebelião do imaginário é evidente em fóruns de discussão e vários blogs e homepages, onde fantasia, fantasmas e outras fantasmagorias ocupam a maior parte do espaço e do tempo. Razão, funcionalidade, utilitarismo não estão totalmente ausentes, mas lhes atribuem uma porção congruente. $\mathrm{Ou}$, mais precisamente, por uma interessante inversão de polaridade, eles servirão como coadjuvantes de uma realidade lúdica. De mestres, eles se tornam servos.

É, a esse respeito, instrutivo observar como o festivo, o imaginário e o onírico coletivos se tornarão as normas do espaço cyber. E assim contaminar a esfera privada e pública. Na racionalização generalizada da existência, quando o contrato social é constituído, vemos o que é chamado, coloquialmente, de "muro da vida privada". Sob os golpes de dramatizações e blogs, esse muro, quando não é completamente derrubado, fica poroso, para dizer o mínimo. Boatos, rumores, fofocas, notícias falsas e reais, num curioso mecanismo de contaminação, o espaço cyber desempenha o papel da praça pública, do comércio de café ou da antiga ágora. Em seu sentido etimológico, o foro interno é suplantado pelo foro externo: tudo se torna um fórum, acessível a todos e a cada um. O grande especialista francês do imaginário, Gilbert Durand, indicou que a imagem é um mesocosmo entre o microcosmo pessoal e o macrocosmo coletivo. No sentido estrito, é um "mundo do meio". Ela faz um laço. Ela estabelece uma religação. Há, portanto, uma dimensão comunitária no 
compartilhamento de imagens eletrônicas. Além do confinamento individual, elas são a causa e o efeito de um verdadeiro corpo social.

É certo que este não é redutível à racionalidade própria daquilo que se aceita nomear como a Sociedade. Irá se difratar na multiplicidade de tribos de várias ordens, baseada na partilha de um gosto comum. Tribos musicais, esportivas, culturais, sexuais e religiosas são baseadas em imagens produzidas e vividas juntas. O cogito, ergo sum cartesiano foi baseado em uma importante revolução epistemológica: pensar por si mesmo. E isso no confinamento, na fortaleza da mente individual. É o oposto que se expressa na web, onde o compartilhamento de imagens faz com que uma seja pensada pela outra. Essa existe apenas por e sob o olhar dos outros. Isso não se dá sem gerar o que podemos chamar, para usar a expressão de Durkheim, um “conformismo lógico". Mas isso também, ao contrário do que é conveniente afirmar, não é a expressão de um simples narcisismo. Ou o significado da palavra narcisismo deveria ser mudado. Ao contrário do que dizem as interpretações usuais desse fenômeno, Narciso não está perdido à sua imagem, mas no lago onde sua imagem é projetada. A diferença é importante porque esta lagoa simboliza a natureza como um todo, o dado mundano, onde a pessoa, enquanto se perde, floresce em um todo maior.

Isso é o que chamei de "narcisismo de grupo", um narcisismo coletivo, que está em jogo em todos os fenômenos da virtualidade eletrônica. Para retomar a metáfora da semente de Onan, certamente há perda, mas é feita em um conjunto além do indivíduo e, portanto, participa do conforto do corpo coletivo. Este é um processo de masturbação coletiva que enfrentamos nos famosos sites comunitários. Cada um, impunemente pelo anonimato, revelando-se ao outro. Existe conectividade, tatilidade no ar! Os filósofos da Idade Média se perguntavam sobre o glutinum Mundi. O que é essa cola do mundo que, apesar dos vários egoísmos, "se mantém"? Às vezes, essa cola é o fato de um ideal distante, foi o caso da modernidade. Às vezes, pelo contrário, essa cola é elaborada a partir do compartilhamento de afetos, emoções, paixões comuns. Fossem bastante inócuos e de pouca importância. Essa é a religação que está em jogo em todos esses sites. A palavra, além disso, não é neutra. O tempo se contrai no espaço. Torna-se um "site" que eu compartilho com os outros e a partir do qual eu posso "crescer". A história, com um grande "H", a história da modernidade, autoconfiante, dá lugar a essas pequenas histórias, sem conteúdo real, mas garantindo o link, permitindo o elo. Nestes sites comunitários, para brincar com a eufonia de palavras, o lugar faz o elo. 
Second life, Myspace, Facebook são todas variações do jogo de imagens e do dispêndio improdutivo. Tudo isso é inútil, mas enfatiza o preço das coisas sem preço. Esses sites são as formas pós-modernas do Potlatch pré-moderno. O que restou, como forma residual, na sabedoria popular que "conhece" muito bem, de saber incorporar, que, às vezes, quem perde ganha. E que na inutilidade do "chat", na irrelevância do blog ou do fórum de discussão, mesmo na obscenidade da "home page", é (re)encontrada a consolidação do vínculo social.Algo sacramental de certa forma. Isto é, tornar visível uma força invisível. Nesse sentido, o mundo virtual das ciberculturas é uma maneira de expressar o desejo do estar-junto. Essa nova conexão espiritual foi comparada à "noosfera" do padre Teilhard de Chardin. Essa reaproximação não é anacrônica, pois deixa claro que há nos elos invisíveis das trocas virtuais algo que, mais que a dimensão econômica, mais que a quantificação positivista, mais que as infraestruturas materiais asseguram uma coesão social cujas consequências ainda não foram mensuradas.

Jogadores on-line que, de Tóquio a Londres, passando por São Paulo ou Los Angeles, sem esquecer uma remota aldeia dos Alpes ou dos Cárpatos, exaurem-se em jogos intermináveis, conectados que estão pelos elos mágicos do virtual. Mas a realidade deles é muito mais eficaz do que os princípios de realidade comumente aceitos. Não será apenas porque suas vidas cotidianas são, em seu sentido mais forte, determinadas por esses jogos que os fascinam? Eles são como que magnetizados por polaridades distantes e invisíveis. Essa é a noosfera da cibercultura virtual. Em um momento importante para a modernidade, o surgimento da Reforma, Max Weber chamou a atenção para o poder do imaterial. Seu livro principal é testemunha disso: "A ética protestante e o espírito do capitalismo". Uma certa interpretação da Bíblia, o protestantismo, engendra uma nova organização do mundo: o capitalismo. O que ele resume bem, lembrando-nos que só podemos "entender o real apenas do irreal". Pode-se acrescentar, o que é considerado como tal, mas ainda assim tem uma força inegável. E servirá como base para a nova ordem das coisas.

É uma tal natura rerum que está em jogo na web. A partir do virtual, o link social é ao mesmo tempo sólido e pontilhado. É essa nova forma que muitos observadores sociais não entendem e que têm alguma dificuldade em compreender, analisar ou, simplesmente, admitir uma socialidade da qual todos os ingredientes são os desse imaginário lúdico ou onírico que foi discutido e que atravessa, de um lado para outro, a cibercultura. Especialmente em um ponto essencial, o que se relaciona com o suposto individualismo contemporâneo. Todos esses são lugares comuns, tomando o lugar das análises científicas, passando pelo mundo 
"cibernético", onde as relações se criam, as trocas são elaboradas, a partilha acontece e todas as coisas vão constituindo, para melhor e para pior, uma nova vida social.

Para melhor e para pior, certamente, porque o compartilhamento de arquivos pode suscitar questionamentos. O Peer to Peer gira as regras econômicas usuais. Mas, gostemos ou não, é um negócio estabelecido. Comércio que deve ser entendido stricto sensu: comércio de bens, comércio de ideias, comércio de amor. Essas expressões francesas antigas dizem, claramente, que, ao lado do merchandising de objetos, existem também trocas filosóficas, religiosas ou emocionais na Internet. E não é peculiar a qualquer estado nascente ser, potencialmente, excessivo, paroxístico ou mesmo anômico? De acordo com um famoso ditado, o anômico de hoje é o canônico de amanhã. A esse respeito, o que pode ofender os valores morais estabelecidos, no entanto, constitui uma força ética para as tribos pósmodernas em questão. É um imoralismo ético que encontramos nas intermináveis discussões do Myspace. Tudo, e não importa o quê, é dito. É o imaginário e o onanismo coletivo o tempo todo, e ainda assim é criado um ideal comunitário. Solidariedade que encontra sua origem. $E$ pur se muove dizia o grande Galileu aos seus detratores. $\mathrm{O}$ dogmático, em última análise, não poderia mais. O geocentrismo terminou. É algo desta ordem que pode ser dito hoje: ainda vive. Mesmo sendo virtual, existe uma enxurrada cultural, existencial e social na web. Eu poderia falar no Japão sobre "geração de Otaku". Tão perto quanto possível de sua etimologia, está confinado à “casa". Mas, como um enraizamento dinâmico, a partir daí, suas mensagens, seus links, seus relacionamentos se espalharam pelo mundo para criar comunidades virtuais e reais. Esta é uma complexio oppositorum, a teia de elementos opostos, mas complementares. Essas reuniões de e para os sites da comunidade permitem viver várias vidas, Second life. E ao fazê-lo, reacende o vagabundo, fundador de toda a verdadeira cultura. Desperta um "Wanderlust", um prazer de perambular que é o trabalho de exploradores, todos os conquistadores, aqueles que descobrem novos mundos. Apelo ao desconhecido ou como Durkheim disse, "sede do infinito". É isso que está em jogo para esses cavaleiros pósmodernos. Eles navegam na Internet à procura de um Graal que, como qualquer Graal, não tenha contornos ou conteúdo preciso. Apenas o caminho, apenas a vagabundagem, apenas o "surf" é importante aqui. Como indiquei acima, a imagem e / ou onanismo dá origem a uma forma de prazer que é mais forte porque é inútil. Talvez seja isso que, a longo prazo, os fez estigmatizar na tradição judaico-cristã e depois moderna. Especifico que a libido em questão não é, simplesmente, sexual, mas conota de um modo muito mais amplo, uma energia, um impulso vital, em suma, uma vontade de viver irreprimível. 
Este é um tipo de instinto que não se preocupa com o raciocínio preciso. É isso que aflige os observadores sociais que têm dificuldade em admitir que algo pode ter sentido (significação) sem ter um sentido (finalidade). Assim, o filósofo alemão Romano Gardini definiu o espírito da liturgia: "Zwecklos aber sinnvoll”. É uma liturgia que é configurada em blogs, fóruns de discussão e vários sites da comunidade pontuando a web eletrônica. $\mathrm{O}$ conteúdo não importa, apenas o "continente" é necessário. "Continente", isto é, que espacializa o tempo. Cria o estar-junto onde o fato de estar em contato é a realidade primordial. Com a Internet, passamos de uma tradição logocêntrica, onde a palavra era soberana, para outra tradição, muito mais localizada, apenas o espaço, apenas o "site" compartilhado com os outros prevalece. Daí a impressão de "falar para não dizer nada". De fato, não dizemos nada, mas esse nada é essencial, é matriz. Ele dá a ser. E ao mesmo tempo, ele faz cultura. Através de homepages reais ou falsas, todo mundo investe figuras arquetípicas e, portanto, faz parte da linhagem, a concatenação garantindo a sustentabilidade da comunidade humana.

Não é à toa que pequenas tribos que navegam na Internet usam as máscaras, nomes e roupas de antigos cavaleiros ou mitologias antigas. Há primitivismo no ar. Mas apenas enfatiza a força e o vigor dessas coisas arcaicas que se pensava estarem ultrapassadas. Eles servem de base e, de tempos em tempos, lembram-se da boa memória dos humanos: só se constrói sobre o dado. Logo no início do Nascimento da Tragédia, Nietzsche recorda a importância do que ele chama de "figuras incisivas". Figuras simbólicas em torno das quais se agregam. Figuras que fundam a comunidade. É exatamente isso que está na origem da cultura. Posteriormente, tende a se tornar civilização, até que um ciclo termina, uma nova cultura renasce. Talvez seja o que está acontecendo com a cibercultura. A civilização moribunda burguesa deixa o lugar na Internet para o retorno de figuras arcaicas que enfatizam que estamos testemunhando um verdadeiro reencantamento do mundo. "Circunavegação", disse eu, induzindo uma nova ordem. A do intangível, do virtual com eficiência contagiante.

Não é inútil olhar para trás para apreciar o que está em via de acontecer. De minha parte, eu sempre disse que a nascente pós-modernidade poderia ser comparada a esse outro momento de fundação que foi o fim do Império Romano, o terceiro e o quarto séculos de nossa era. As instituições oficiais estão lá, parecem sólidas, e, no entanto, eles já são corroídos por dentro. As ideologias estabelecidas são os únicos discursos permitidos, mas ninguém presta atenção. Tudo tem o sabor insípido do déjà vu e já entendido. E é em outro lugar que os espíritos exigentes procuram fazer seu mel. Muito precisamente dentro desses 
cultos de mistério, fervilhando neste tempo no final do Império Romano. Orfeu, Mythra, cristianismo nascente. Estas são, entre outras, as comunidades onde não se contenta com encantamentos desgastados e um tanto mortíferos. Estes são os "sites" onde a verdadeira religião vive. Aquele que está em sintonia com a vida cotidiana. Em suma, aquele em que se retorna em religação com a alteridade. Ou seja, com o outro da proximidade (o social) e com o Outro do distante (a divindade). O "mistério" é o que une os iniciados entre si, aqueles que compartilham os mesmos mitos. Mas o que fez com que no florescimento desses cultos, e enquanto eles tinham especificidades bastante semelhantes, apenas o cristianismo sobreviveu? Certamente, as razões devem ser múltiplas. Posso privilegiar uma? Como um corpo que segrega o que permite sua sobrevivência, as pequenas seitas cristãs irão secretar o dogma da comunhão dos santos. Unindo os mortos aos vivos e estes uns aos outros.

Assim, a comunidade de Roma está unida em espírito com a de Lyon, Narbonne e Milão. Assim, é criada uma união pontilhada que dará origem a uma Igreja de importância e uma cultura da qual deriva toda a Europa. Graças a esta "comunhão", será estabelecido um comércio entre as várias igrejas locais. Intercâmbios e compartilhamento constituem um corpo místico, desenhando todas as consequências doutrinárias e organizacionais da religação que foi discutida. Vamos nos voltar ao que está acontecendo diante de nossos olhos. O mesmo processo de iniciação, as mesmas trocas e compartilhamentos de todos os tipos. Peer to peer é a ordem do dia em muitas áreas. Um termo traduz bem tudo isso: flashmob, mobilização instantânea. Mesmo na ordem do conhecimento, com os erros grosseiros e erros que conhecemos, a Wikipédia está na crista da onda, símbolo, se for o caso, que o conhecimento não vem de cima, não emana mais de uma potência vertical, mas se espalha à imagem da potência de base, de forma horizontal.

Estes são apenas alguns indícios da cibercultura emergente. O desenvolvimento tecnológico que contribuiu para a desmagificação do mundo e contribuiu para o isolamento dos indivíduos, para o que pode ser chamado de solidão gregária, inverte-se na direção oposta, e contribui para uma nova religação: estar, sempre, em contato, em união, em comunhão, para estar conectado. Sim, é uma nova cultura que está se desenvolvendo com a Internet. O "ciberespaço" é um elo, com contornos indefinidos e infinitos, onde, de maneira matricial, se desenvolve o encontro com o outro, onde se reforça o corpo social. Não pode ser dito, portanto, que constitui a comunhão dos santos pós-modernos? Arcaísmo, novamente, que pode nos ajudar a entender outra tradição religiosa, o hinduísmo, como no uso de avatares. Não voltarei à pluralização da pessoa. Eu já disse como isso caracteriza a pós- 
modernidade. Mas, quanto ao uso mágico da tecnologia, é interessante observar os principais elementos do avatar: múltiplas encarnações, transformações e acidentes. Seja em jogos eletrônicos ou em locais virtuais, todos podem "incorporar" essa ou aquela faceta de sua pessoa. Coloque uma máscara e, por isso, expresse uma fantasia que é proibida na vida cotidiana. Eu digo exprimir. Um pouco como o suco (esprimido) de uma laranja, mostre o que existe, por si só, e é inútil negar. São essas "expressões" que possibilitam entender as transformações vivenciadas pela mesma pessoa. Fim da identidade única, a do indivíduo indivisível! São as múltiplas identificações que podem, impunemente, prevalecer. $\mathrm{Na}$ modernidade racionalista, apenas a ficção foi autorizada a encenar dentro do mesmo indivíduo, o Dr. Jekyll e o Sr. Hyde. E, ainda assim, foi de um jeito criminoso.

Da mesma forma, a psiquiatria identificou na esquizofrenia a divisão da personalidade. Pela dissociação, pensamos que é, estritamente falando, "split" com todos os riscos pessoais e coletivos inerentes a tal fissão do núcleo individual. O indivíduo normal, na modernidade, tem uma identidade sexual, ideológica e profissional. Qualquer fragmentação é patológica. É certamente por isso que a esfera de vídeo, o papel ou sagas como "World of Warcraft" são constantemente condenados pela benevolência educacional. No contexto da iconoclastia semítica, a que me referi, o virtual é sempre suspeito. É repleto de fantasmagorias inacreditáveis e, portanto, potencialmente perigoso. Note-se uma das expressões de tal "transformismo": sabemos que em sites de namoro, em particular, muitas "máscaras" pseudo "femininas" travestem, na verdade, um homem. Reconhecidamente, é facilmente possível interpretar esse tipo de fantasia através das categorias psicanalíticas e moralizantes usuais. Mas, no âmbito do pensamento não crítico próprio da sociologia, o homem que se torna mulher é uma constante mitológica, um lugar-comum de todas as mitologias.

Portanto, não é de surpreender que tal transformação ganhe novo vigor no contexto de uma era em que a feminização dos valores e da moral desempenha o papel que conhecemos. O que nos leva, após as encarnações, as transformações, para a terceira especificidade do avatar: o acidente. A máscara que usamos, na verdade, é momentânea. Ocorre de acordo com esta ou aquela ocasião. Favorece o presente, e mesmo o momento. Ocorre de acordo com o que acontece no jogo eletrônico ou oportunidades que aparecem no local virtual de encontro. Posso lembrar que, na filosofia, "acidente”, em oposição à substância, é contingente, relativo. É um relativismo que, como um fio vermelho, atravessa a cibercultura. O relativismo, nunca cansaremos de repetir, é o que ao mesmo tempo relativiza uma Verdade única, uma 
Identidade estável e, portanto, coloca em relação. Essa relação é, particularmente, notável na multiplicação de sites comunitários. O processo está em curso, lábil.

Assim como foi o caso da galáxia de Gutenberg em sua época, a galáxia eletrônica é correlata a outro modo de estar-junto: o da pós-modernidade. Um elemento, no entanto, que parece constante é o sentimento de pertença. O que está em questão é o retorno das tribos. Estas, como sabemos, são de geometria variável. Cada pessoa, além disso, pode participar de várias tribos, e isso em função, precisamente, das máscaras de que ela vai se revestir. Mas o menor denominador comum de todos esses lugares virtuais é o desejo de comunhão. Um relacionamento onipresente. Essas redes sociais são múltiplas e florescem. O site "Buddies before", com seu toque de nostalgia. "Twitter", onde você pode twittar à vontade em todos os tópicos atuais. Do mais sério ao mais frívolo. "Orkut", agrupando-se por cooptação dos "fãs" de uma celebridade, um tema, uma paixão específica. "Facebook", é claro, reivindicando 250 milhões de usuários em todo o mundo.

E os sites de microblogs onde, mais de um quarto de hora de glória para o Andy Warhol, todos esperam certa fama, tornando públicas canções, pinturas ou suas análises filosóficas. Sites comunitários, blogs, orkut e outros Twitters estão lá para nos lembrar que o reencantamento do mundo está bem ancorado na sociabilidade pós-moderna. Como as tribos primitivas em torno de seus totens, os usuários da Internet contemporâneos se reúnem em torno de seus ídolos específicos. Estes, como a temporalidade peculiar ao nosso tempo, são bastante efêmeros. O "hype" tem suas regras intangíveis: você deve estar sempre na vanguarda da moda. Mas esse não é o ponto. O que prevalece é a unidade da comunidade para fazer, ser, pensar como o outro e, acima de tudo, de acordo com o outro. Tudo, pois, é relativo. Até o saber.

O que também é notável na tecnomagia induzida pelo desenvolvimento dos meios de comunicação interativos é, por um lado, a produção coletiva de conhecimento e, por outro lado, a adesão comum a ele. O conhecimento não vem mais simplesmente do topo, seguindo o caminho natural e inerente da “ Lei do Pai”. Esta é a herança da tradição semítica, culminando nas "grandes narrativas de referência" específicas da modernidade. Mas, pelo contrário, esse conhecimento vem de baixo, é transversal. Mudança de tópico que afeta, além disso, todos os órgãos oficiais do conhecimento. Hegel, que deve ser lembrado, disse que a leitura do jornal era a "oração do homem moderno". O que era profético na época mostrou-se relevante ao longo de seu século, o século XIX, e o que se seguiu, o século 20. Essa foi uma mediação para se conectar com o mundo em sua totalidade: estar em sintonia com o Zeitgeist, 
o espírito da época que, lembremo-nos, era absoluto e universal. Mas o tempo retorna. O tempo se "presentifica". O espírito e particularizado. Isso também leva ao relativismo das certezas científicas. O jornal como oração matinal dá lugar ao surf-riding na Internet, onde vamos bicar, aqui ou ali informações mais ou menos comprovadas, muitas vezes imperfeitamente verificadas, às vezes totalmente falsas.

$\mathrm{Na}$ antiga Ágora, Sócrates podia filosofar. Por sua conta e risco. Nós sabemos o resto. Da mesma forma, o pensamento da praça pública tende a prevalecer na Internet. O "Café du Commerce" será chamado de "cyber-café", porque há entre eles homologia estrutural, é KifKif, o melhor está lado a lado com o pior, a admiração fundamentada vai de par com o boato e a calúnia a mais sem vergonha. Mas é assim. Há um fervilhamento cultural, e antes que a sedimentação seja feita, "isso" enxameia. O tempo irá nos dizer. A realidade está aí e merece atenção. Um pequeno Davi contra um Golias. E é certamente feliz; de qualquer forma, este conto é o índice de uma mudança de importância na produção e comunicação do conhecimento. Um tópico horizontal está sendo posto em prática. Mas, para tranquilizar meu eminente amigo, e outros como ele ameaçados pelos mosquitos que os impedem de cochilar, páginas da Wikipédia são "relativizadas" por muitos outros, na web. O essencial é que os dogmáticos, expressando-se da maneira que sabemos, sem perceber, levam à relativização, de fato, desta Ciência da qual eles se consideram ousados defensores. Isso é chamado de heterotelia, efeito perverso. Efeito diferente do esperado. Diversão? Apesar de tudo, instrutiva.

Este é o relativismo induzido pela internet. Avatares e tribos reunindo-se em torno de seus totens e a fragmentação do conhecimento são todas as manifestações, para usar uma expressão de Max Weber, de um "politeísmo de valores" galopante. É o que nos permite entender a definição de pós-modernidade: a sinergia do desenvolvimento arcaico e tecnológico. Essa tecnologia que desencantou o mundo está tentando, curiosamente, reencantá-lo. O que oferece, e a coisa não é, necessariamente, pejorativa, um show coletivo desses vários amontoamentos. Na Idade Média, os "mistérios", em torno dos quais a comunidade se comunicava, eram celebrados em frente à catedral. É o mesmo hoje em dia. É nas igrejas eletrônicas, através de videogames, sites, blogs, fóruns etc. que os "mistérios" pósmodernos se desenrolam. Mistérios unindo todos esses iniciados (sexual, musical, esportivo, religioso ou teórico falando) que desenham a socialidade em gestação. 


\section{REFERÊNCIAS}

BAUDELAIRE, C. Les fleurs du mal. Paris: Garnier, 1954.

CHARDIN, T. Le phénomène humain. Paris: Points, 2007.

DESCARTES, R. Discours de la méthode. Paris: Flammarion, 2000.

DURAND, G. Les structures anthropologiques de l'imaginaire: Introduction à l'archetypologie générale. Paris: Dunod, 1992.

DURKHEIM, E. Les règles de la méthode scientifique. Paris: PUF, 2013.

GARDINI, R. L'esprit de la liturgie. Paris: Parole et silence, 2007.

HEGEL, G. W. F. Phénoménologie de l’esprit. Paris: Gallimard, 1993.

HUGON, S. Circumnavigations. L'imaginaire du voyage dans l’experience Internet. Paris: CNRS Éditions, 2010.

KUHN, T. La structure des révolutions scientifiques. Paris: Flammarion, 1999.

MAFFESOLI, M. La violence totalitaire. Essai d'anthropologie politique. Paris: PUF, 1979.

MAFFESOLI, M. Le réenchantement du monde. Une éthique pour notre temps. Paris: Perrin, 2009.

MALEBRANCHE, N. Conversations chrétiennes. Paris: Gallimard, 1995.

NIETZSCHE, F. Ainsi parlait Zarathoustra. Paris: Gallimard, 2017.

NIETZSCHE, F. La naissance de la tragédie. Paris: Gallimard, Col. Folio, 1986.

SCHMITT, C. Le nomos da terra. Paris: PUF, 2000.

WEBER, M. L'étique protestant et l'esprit du capitalisme. Paris: Gallimard, 2003.

WEBER, M. Le savant et le politique. Paris: Plon, 1959. 